\title{
Correction to: Increased Fecal Bile Acid Excretion in a Significant Subset of Patients with Other Inflammatory Diarrheal Diseases
}

\author{
Priya Vijayvargiya ${ }^{1}$ - Daniel Gonzalez Izundegui ${ }^{1}$. Gerardo Calderon ${ }^{1}$ - Sarah Tawfic ${ }^{2}$. Sarah Batbold ${ }^{2}$. \\ Hiba Saifuddin ${ }^{2} \cdot$ Patrick Duggan $^{2} \cdot$ Valeria Melo ${ }^{2} \cdot$ Taylor Thomas $^{2} \cdot$ Megan Heeney $^{2} \cdot$ Adrian Beyde $^{2}$. \\ James Miller Jr. ${ }^{2} \cdot$ Kenneth Valles ${ }^{2} \cdot$ Kafayat Oyemade $^{2} \cdot$ Joseph F. Brant $^{2} \cdot$ Jessica Atieh $^{1} \cdot$ Leslie J. Donato $^{3}$. \\ Michael Camilleri ${ }^{1}$ (D)
}

Published online: 16 October 2021

(c) The Author(s), under exclusive licence to Springer Science+Business Media, LLC, part of Springer Nature 2021

\section{Correction to: Digestive Diseases and Sciences https://doi.org/10.1007/s10620-021-06993-5}

In Table 3 of this article, the data '20.4 (4.8-81)' in the column 'Ileal resection' and row '\% primary BA' should have read as '95 (75-99)'.

The original article has been corrected.

Publisher's Note Springer Nature remains neutral with regard to jurisdictional claims in published maps and institutional affiliations.

The original article can be found online at https://doi.org/10.1007/ s10620-021-06993-5.

Michael Camilleri

camilleri.michael@mayo.edu

1 Clinical Enteric Neuroscience Translational and Epidemiological Research (CENTER), Division of Gastroenterology and Hepatology, Mayo Clinic, 200 First St. S.W. Charlton Bldg., Rm. 8-110, Rochester, MN 55905, USA

2 Mayo Medical School, Rochester, MN, USA

3 Department of Laboratory Medicine and Pathology, Mayo Clinic, Rochester, MN 55905, USA 